\title{
Exogenous Sucrose Supply Regulates the Non- Structural Carbohydrate, Endogenous Hormone and Mineral Element Levels before the Flower Blooming and Fruit Abscission Stages in the Biodiesel Tree Sapindus mukorossi Gaertn.
}

\author{
Yuan Gao \\ Beijing Forestry University \\ Ying Yang \\ South China Agricultural University \\ Shilun Gao \\ Beijing Forestry University \\ Liming Jia ( $\boldsymbol{\sigma}$ jlm@bjfu.edu.cn ) \\ https://orcid.org/0000-0002-6680-041X \\ Shiqi Liu \\ Beijing Forestry University \\ Xuehuang Weng \\ Yuan Hua Forestry Biotechnology Co.Ltd
}

\section{Research article}

Keywords: Sapindus mukorossi Gaertn., exogenous sucrose supply, non-structural carbohydrate, endogenous hormone, mineral element

Posted Date: April 6th, 2020

DOl: https://doi.org/10.21203/rs.3.rs-20992/v1

License: (c) (i) This work is licensed under a Creative Commons Attribution 4.0 International License.

Read Full License 


\section{Abstract}

Background: Nutrient deficiency leads to a high fruit abscission rate in Sapindus mukorossi Gaertn. (Soapberry), which is one of the most widely cultivated biodiesel feedstock forests in China. Exogenous sucrose can provide a solution to nutrient deficiency and fruit abscission, which was applied to whole trees at two stages, 20 days before blooming (DBB stage) and fruit abscission (DBFA stage). Six sucrose concentrations, $0 \%, 1 \%, 1.5 \%, 3 \%, 5 \%$ and $7 \%$, were sprayed three times at a completely randomized block design with 5 replications and 6 treatments. ${ }^{13} \mathrm{CO}_{2}$ labelling experiments were carried out after the 3 sprayings.

Results: (1) In the DBB stage, the $3 \%$ treatment significantly increased the inflorescence fructose and glucose contents 1-1.2 times, also resulted in the highest fruit $\mathrm{GA}_{3}$, leaf IAA, fruit IAA and fruit ZT contents, while it decreased the inflorescence ABA from $16 \mu \mathrm{g} / \mathrm{g}$ to $4 \mu \mathrm{g} / \mathrm{g}$. (2) The $1.5 \%$ and $3 \%$ treatments significantly increased the carbohydrate content and decreased fruit ABA content to $30 \%-50 \%$ of the control level in the DBFA stage. (3) High-concentration sugar treatment (over 3\%) increased the nitrogen, phosphorus, and potassium contents, which decreased the calcium and magnesium contents. (4) The ${ }^{13} \mathrm{C}$-dispatching ability of the inflorescence was 3 times greater than leaves under highconcentration sugar treatment in the DBB stage. Supplying $1.5 \%$ sucrose nearly doubled the allocation capacity in the DBFA stage. (5) The source-sink nutrient migration pathway showed that leaf and fruit sugars were directly correlated via phosphorus. Fruit fructose and glucose contents affected the leaf mineral element contents.

Conclusions: It can conclude that exogenous application of $3 \%$ sucrose in the DBB stage and $1.5 \%$ sucrose in the DBFA stage can increase the sink nutrition allocation capacity, and phosphorus is the main mineral element correlated with leaf and fruit sugars.

\section{Background}

Soapberry (Sapindus mukorossi Gaertn.) is widely cultivated as a biodiesel tree in southern China; because of its high seed oil content (42.7\%) and multifunctionality (saponin material and bioenergy and medical applications), it has formed an industrial chain [1-3] and has already been planted on nearly 26000 ha in China. However, the high fruit abscission rate of soapberry results in poor yields and has become the bottleneck to the sustainable development of this plant for industrial uses. There are three fruit abscission stages during the growing season: the first is in the initial fruiting stage, with a drop rate of $49.02 \%$; the second is the fruit core-hardening stage, with a drop rate reaching $72.74 \%$; and the last is the mature period, with a drop rate of $17.69 \%$ [3]. The first fruitlet abscission stage (June) is caused by incomplete pollination. The second fruit abscission stage, which is called the physiological fruit-falling period (August-September), is hypothesized to result from a shortage of carbohydrates and nutrients. The third stage takes place before fruit maturation and is caused by a high ethylene content [4-6]. 
Fruit set is one of the most important factors that determines the net production potential of a fruit crop [7]. It is imperative to improve fruit set by reducing flower and fruitlet drop with the use of crosspollination, plant growth regulators (PGRs), nutrients and chemicals [8]. The first and second abscission stages, with high abscission rates, need to be addressed and regulated for soapberry. Sucrose supplementation could result in lower abscission rates via an increase in carbon availability for developing fruitlets [9]. The main reason for spraying sugar onto plants before blooming is to boost carbohydrates, which are the main energy source for most insects [10]; carbohydrates can attract bees and ensure complete pollination [11]. Du et al. [12] revealed that sucrose application significantly improved flower production and increased bud size and fresh weight, which increased the fruit set rate during the first abscission stage. Carbohydrates, mineral nutrients and hormonal growth regulators play important roles in the physiological regulation of reproductive growth. In particular, with adequate supplies of sugar, woody plants maintain floral induction, fruit set, and high yield [13]. Eccher et al. [14] proved that the physiological fruit-falling period (second abscission stage) of apple results from the deficiency of sugar signals. Non-structural carbohydrates (TNCs) are the main type of energy transferred in the fruit growth stage $[15,16]$. Exogenous sources of sugar are greatest for plants, and appropriate nutrient supplementation can further improve plant starch production [17]. Furthermore, sugar metabolism is closely related to the ripening and senescence of fruit, which are directly regulated by ethylene [18], especially when light conditions are poor or light intensity is low [19]. Wójcik et al. [20] demonstrated that spraying sucrose onto cherry in the growing season guaranteed an optimal soluble sugar content (SSC) of fruit under conditions of low solar radiation, a high canopy density or overcropping. Most of the soapberry feedstock forests in China occur in low-light density areas, which have a high canopy density and narrow canopy gaps [21]; thus, the sugar supply is important for nutrition transfer in these forests. Amiri et al. [22] showed that the application of sucrose before initiation of the June fruit drop resulted in a $19.5 \%$ reduction in abscission and a $13 \%$ increase in yield. Sugar application also significantly increases root and leaf yields in radishes [23].

TNCs include starch and soluble sugars (sucrose, glucose, fructose and sorbitol). These carbohydrates play an essential role in supporting new growth by providing structural components and energy [24]. The application of exogenous sucrose may result in a larger flow of carbon compounds from glycolysis to organic acids and elevated amino acids [25]. Previous research proved that sucrose and sorbitol are the main forms of assimilated carbohydrates (photosynthetic products) transported from leaves to fruits [26]. Leaves are regarded as a source, and fruit growth depends largely on the carbohydrates synthesized by leaves on the same branch that bears the fruit [27]. Sugar metabolism in leaves is very fast, dynamic and complex, and it can strongly alter the leaf carbohydrate profile [28]. Fruits or seeds are regarded as sinks, and strong sinks can absorb large amounts of TNCs from the branches, stems, and leaves of trees [29]. The capacity of fruits to mobilize carbohydrates varies seasonally and between treatments in accordance with differences in the rates of fruit growth. Changes in the availability of assimilates will also trigger changes in the plant hormonal balance [30]; at the same time, plant hormones not only control fruit growth and development but also regulate the transport and distribution of carbohydrates from 'source' to 'sink' [31, 32]. Sucrose and fructose play significant roles in the cold response and 
response to $A B A$ [33], and $A B A$ has a clear effect on the activity of sucrose synthase. IAA has no significant effects on the glucose content in grains, but it has effects on invertase and leads to an increase in the conversion of sucrose to fructose [34]. Sufficient evidence has revealed that different phytohormones can serve as modulators of specific rate-limiting components in photoassimilate metabolism [35]. Minerals are recycled from the xylem to the phloem in leaves and then transported to developing fruits together with carbohydrates. Minerals are also essential during flowering [36, 37]; e.g., potassium is involved in the transport of sucrose to the apical region [38]. Calcium affects the transport of sugar within the plant and the development of flowers [39]. $\mathrm{N}$ application can decrease plant concentrations of glucose, fructose, and sucrose [40].

Previous research on nutrient transfer has mainly focused on branches or nursery stock. There has been less research on nutrient transfer in whole fruit trees. Most studies have focused on the changes in single nutrients after treatments or increases in the fruit set rate after nutrients are supplied, and few studies have analysed the correlations between all nutrients. Supplying sucrose to whole plants will cause different sugar metabolism responses and hormone and mineral element changes compared with those observed in simplified models using leaf segments [41]. Supplying exogenous sucrose before blooming and at the fruit expansion stage will influence the relative transfer of all nutrients, especially in soapberry, which requires a large amount of carbohydrates to grow for many years under low-light intensity conditions. Our research addresses the following questions: First, which sucrose concentration contributes to increasing TNC, endogenous hormone and mineral element contents during the blooming and fruiting stages? Second, how do the carbohydrate allocation and transfer abilities of leaves (source) and fruits (sink) change after sucrose application? Third, what are the direct and indirect relationships between TNCs, endogenous hormones and mineral elements? The answers to these questions will reveal the sink transport ability, elucidate the relevant nutrient pathways and provide theoretical and technical support for decreasing the fruit abscission rate. These results lay a foundation for further study of the relevant mechanisms and signalling pathways and provide guidance for the practical application of sugar.

\section{Results}

\subsection{Comparison of Non-Structural Carbohydrates among Different Treatments}

As shown in Fig. 1, the fructose, glucose and sucrose contents on the day before blooming were significantly higher than those at the fruit abscission stage, and the fruit content was $20 \%-70 \%$ higher than the leaf content.

Spraying did not significantly impact leaf fructose (Fig. 1a). In inflorescences and fruits, the fructose content of the control was 6 times lower than that of the treatment groups. The $3 \%$ and $5 \%$ exogenous sucrose applications before the blooming stage significantly increased the inflorescence fructose content, which was 0.5-1 times greater than that of the other treatment groups in the first two sprayings. After the 
third spraying, the inflorescence fructose content of the 3\% sucrose treatment group was 1-1.2 times higher than that of the other treatment groups. Before the fruit abscission stage, the $1.5 \%$ sucrose treatment resulted in a significantly $(0.5-1 \mathrm{mg} / \mathrm{g} \mathrm{DW})$ higher fructose content than that observed for the other treatments after three sprayings.

The leaf glucose content (Fig. 1b) showed no significant differences, and the $0 \%$ treatment (control) group maintained a decreasing trend for the inflorescence glucose content. Clearly, the $3 \%$ and $5 \%$ treatments resulted in glucose contents that were at least $30 \%$ higher than those of the other groups in fruits at DBB 20 and DBB13, respectively. Until the third spraying, the inflorescence glucose content in the $5 \%$ treatment was decreased to half that in the $3 \%$ treatment. In the fruiting stage, after the first spraying, the high sugar concentration of $7 \%$ resulted in high glucose levels, but thereafter, the $1.5 \%$ and $3 \%$ treatments significantly increased the glucose levels.

The amount of leaf sucrose (LS) showed no significant differences during the 6 sprayings (Fig. 1c). After the first spraying, the inflorescence sucrose level significantly increased under the $1.5-5 \%$ treatments, but there was no difference from the control levels after the DBB13 spraying. After DBB5, the 3\% treatment resulted in sucrose levels $20 \%-40 \%$ higher than those in the other treatments. Compared with the control, the $1.5 \%$ and $3 \%$ treatments resulted in a higher fruit sucrose content in the 3 sprayings before the fruit abscission stage.

\subsection{Comparison of Endogenous Hormones among Different Treatments}

Figure 2a shows that the $\mathrm{GA}_{3}$ content at DBB20-DBB5 was higher than that at DBFA20-DBFA5. After the second spraying, inflorescence $\mathrm{GA}_{3}$ significantly increased (4-8 times) under the high-concentration treatment compared with the control, but leaf $\mathrm{GA}_{3}$ decreased as the fruit $\mathrm{GA}_{3}$ increased. After the third spraying, the $3 \%$ and $5 \%$ treatments significantly increased the inflorescence $\mathrm{GA}_{3}$ to levels over $900 \mu \mathrm{g} / \mathrm{g}$ at DBB5. At the DBFA stage, a significant change in fruit $\mathrm{GA}_{3}$ appeared at DBFA5, especially in the $5 \%$ treatment, in which fruit $\mathrm{GA}_{3}$ was one-fold higher than the control level.

Compared with the changes in $\mathrm{GA}_{3}$, those in IAA were completely different. The L-IAA level at the DBFA stage was higher than that at the DBB stage (Fig. 2b), while F-IAA showed the opposite trend. The L-IAA of the control maintained a declining trend in the DBB stage compared with that under the $1-3 \%$ treatments, which increased after the second spraying. Until DBB5, the 3\% treatment group maintained the largest amounts of L-IAA and F-IAA. In the DBFA stage, the L-IAA of the control was higher than that of all the treatment groups. The F-IAA significantly increased under the high-concentration treatments after the third spraying.

As shown in Fig. 2c, the ZT content was significantly higher in the blooming stage than in the fruit abscission stage. The high-concentration treatments resulted in more stable L-ZT levels during the DBB stage, and the $1.5 \%-5 \%$ treatments resulted in inflorescence ZT content that was at least $50 \%$ higher than 
that of the control after the third spraying. At the DBFA stage, the 3\% treatment increased the L-ZT at DBFA5, but the F-ZT showed no significant change compared with that in the control.

L-ABA showed a declining trend in the DBB20 stage (Fig. 2d). In contrast, it maintained an increasing trend during the DBFA20 stage. Exogenous sucrose decreased the ABA amount in flowers and fruits, and the smallest amounts at the two stages appeared under the $5 \%$ and $7 \%$ treatments. After the third spraying in the DBB stage, the F-ABA content reached only $30-50 \%$ of the control level.

\subsection{Comparison of Mineral Elements among Different Treatments}

In the comparison of the levels of five mineral elements (Fig. 3), before the blooming stage, the $\mathrm{N}$ content was found to have the highest percentage, at over $3 \%$. In the DBFA stage, Ca occurred at levels approximately $6 \pm 1.5 \%$ higher than the levels of the other mineral elements. $P$ had the lowest content in these two stages.

Nitrogen slightly increased in the DBB stage after high-concentration treatment spraying. In the DBFA stage, there was a significant increase under the $1.5 \%$ and $3 \%$ treatments, and the highest-concentration treatment of $7 \%$ sucrose led to a lower leaf $\mathrm{N}$ content. The phosphorus content was highest in the $3 \%$ treatment during the first and second sprayings. In the DBFA stage, treatment with different concentrations had no significant influences on the $\mathrm{P}$ content, but it was clear that the $\mathrm{P}$ content significantly decreased in the control after the third spraying. It can be concluded that without exogenous sucrose, $\mathrm{P}$ decreased quickly in the 20 days before the fruit abscission stage. The $\mathrm{K}$ content in the DBFA stage was higher than that in the DBB stage. In the DBB stage, the $3 \%$ treatment resulted in a significantly higher $\mathrm{K}$ content than observed in the other treatments after the third spraying; in the DBFA stage, the $\mathrm{K}$ content under the $7 \%$ treatment was higher than that under the other treatments. The Ca content was higher under the high-concentration treatment than under the other treatments in the DBB stage, but there was nearly no difference among treatments after the third spraying. The Ca content was significantly higher in the fruiting stage than in the flowering stage, but the spraying treatments resulted in Ca contents lower than those of the control in the DBFA stage. After the $1 \%$ and $1.5 \%$ sucrose treatments, the $\mathrm{Mg}$ content was nearly $0.6 \%$, which was the highest content observed at these two stages.

\subsection{Comparison of ${ }^{13} \mathrm{C}$ Isotope Labelling among Different Treatments}

As shown in Fig. 4a, no correlation was detected between shoot length and leaf ${ }^{13} \mathrm{C}$ content. Inflorescence length was negatively correlated $\left(r^{2}=0.322(24 \mathrm{~h}), r^{2}=0.453(48 \mathrm{~h})\right)$ with flower ${ }^{13} \mathrm{C}$ content (Fig. $\left.4 \mathrm{~b}\right)$. A weak negative correlation was observed between inflorescence length and fruit ${ }^{13} \mathrm{C}$ content $\left(r^{2}=0.157\right.$ $\left.(24 h), r^{2}=0.225(48 h)\right)$, but the former was significantly positively correlated $\left(r^{2}=0.567(24 h), r^{2}=0.608\right.$ (48 h)) with seed ${ }^{13} \mathrm{C}$ content. 
The opposite trend was observed between leaves and inflorescences, which indicated exchange from source to sink (Fig. 5). In the blank control and low concentration treatment, flowers contained $37 \%$ more

${ }^{13} \mathrm{C}$ than did leaves, and when the $3 \%$ sucrose treatment was applied, the flowers contained more than 3 times the ${ }^{13} \mathrm{C}$ observed in leaves, which indicated that higher sucrose contributed to increases in leaf-toflower allocation and transport ability. Similar to findings for the DBFA stage, under the treatments with $1.5-5 \%$ sucrose, the ability of plants to transfer ${ }^{13} \mathrm{C}$ from leaves to fruit increased from $85.7-200 \%$, especially under the $1.5 \%$ treatment. It is clear from the figure that there is a large gap between the leaf and fruit ${ }^{13} \mathrm{C}$ contents. The highest seed ${ }^{13} \mathrm{C}$ content appeared under the $5 \%$ treatment, which indicated that a high concentration of sucrose resulted in an increased absorption ability of seeds.

\subsection{The Correlations among Carbohydrates, Endogenous Hormones and Mineral Elements}

Figure 6a shows that fruit sugar levels are closely related to LF, and leaf sugar is also closely related to FS and FF, which are also correlated with L-ZT and L-ABA (Fig. 6b). Leaf hormones are directly related to LF and LG. Figure $6 \mathrm{c}$ indicates that leaf sugar is also related to F-ABA and that fruit hormones are related to LF. Comparing leaf sugar content with leaf mineral element contents, the former was correlated with LN and LP, and the total mineral element content was correlated with LS (Fig. 6d). Figure 6e shows no correlations between fruit sugar and leaf hormones, but fruit sugar was directly correlated with F-GA, $\mathrm{F}$ $\mathrm{ZT}$, and F-IAA, and the total fruit hormone content was also related to FS (Fig. 6f). Fruit sugar was also related to LP (Fig. 6g), leaf hormones were related to F-ABA, and fruit hormones were related to L-ZT (Fig. 6h). Leaf mineral elements were related to L-IAA, and fruit hormones were related to LN.

The pathway diagram shown in Fig. 7 was constructed from the above correlations to show the clear relationships between nutrients in fruits (source) and leaves (sink). Leaf sugar and fruit sugar are directly correlated through phosphorus, so $\mathrm{P}$ is the main factor affecting the source-to-sink transfer of carbohydrates. Fruit sugars and fruit growth hormones (gibberellins, cytokinins and auxins) are positively correlated; leaf sugar is positively correlated with leaf ZT, leaf N and ABA; and leaf total sugar accumulates when the sink (fruit) absorption ability decreases, which results in an increase in fruit ABA. Fruit sucrose has a direct relationship with fruit endogenous hormones, and the fruit fructose and glucose contents affect leaf mineral elements. Additionally, leaf mineral elements affect leaf IAA and sucrose directly, while leaf $\mathrm{N}$ is directly correlated with fruit endogenous hormones and leaf total sugar. Finally, fruit total sugar and fruit endogenous hormones are correlated via leaf fructose.

\section{Discussion}

\subsection{Non-Structural Carbohydrates, Endogenous Hormones and Mineral Elements Respond to Exogenous Sucrose}


Exogenous sucrose had a significant influence on carbohydrates, endogenous hormones and mineral elements of fruits in this study. The above results show that the leaf carbohydrate content cannot be influenced by exogenous sucrose because the leaves can produce carbohydrates by photosynthesis and do not absorb exogenous sugar, while the fruits (flowers) are the sink that absorbs most of the energy from exogenous sucrose [42]. Fruit glucose and fructose are present in approximately equal amounts that are larger than the amount of sucrose, which agrees with previous research findings [43]. Spray application of sucrose in the blooming stage significantly increased fruit sugar, especially after the first and second sprayings at medium (3\%) and high concentrations (5\%). However, the $5 \%$ and $7 \%$ sucrose treatments decreased the fruit sugar content after the third spraying. These findings indicate that a high concentration of exogenous sucrose decreased the fruit absorption ability, while a medium concentration (3\%) resulted in the maintenance of a high carbohydrate content during the three sprayings in the blooming stage. The blank control maintained a decreasing trend in fructose during the DBFA stage compared with that in the $1.5 \%$ treatment, which resulted in increased carbohydrate levels after the third spraying during this stage.

$\mathrm{GA}_{3}$ was increased in flowers and fruits under the treatments with $3 \%$ and $5 \%$ sucrose. Previous research indicated that $\mathrm{GA}_{3}$ plays a role in fruit growth promotion rather than abscission, but the levels of $\mathrm{GA}_{3}$ are strongly reduced when sucrose is deficient [44]. The above results also proved that $\mathrm{GA}_{3}$ increased after exogenous sucrose application. Ülger et al. [45] showed that $\mathrm{GA}_{3}$ does not affect the IAA level significantly, but increasing $\mathrm{GA}_{3}$ will result in a decrease in $A B A$, which indicates that the change trend is different between these two hormones; the control treatment resulted in a higher leaf IAA content than did the other treatments during these two stages. After exogenous sucrose application, the F-IAA increased because the sugar signal induced the differentiation and expansion of fruits [14]. L-ZT maintained a stable trend under the high-concentration treatment when compared with the control in the DBB stage because it can maintain the nutrition pathway balance when leaves rapidly differentiate, increasing the flower's ZT to guarantee sufficient hormone stimulation for flower bud break. The natural drop of apple fruitlets occurs after $A B A$ and ethylene production increase, which leads to negative feedback in fruit development [46]. A decline in ABA content in fruitlets can decrease the rate of flower drop and increase fruit set [47]; it is clear that F-ABA was significantly lower after treatment spraying than in the control during the DBB stage. F-ABA under treatment spraying maintained an increasing trend in the DBFA stage when compared with that in the control, which exhibited a decreasing trend because of an increase in the ABA content in mature fruit, which promotes the unloading of sugar into fruit [48], combined with TNCs, which were more abundant after spraying. The above observations are in agreement with the hypothesis put forward by Talon et al. [49] that a carbohydrate shortage will reduce hormonal stimulators of growth, such as $\mathrm{GA}_{3}$, and increase stress-sensitive signals, such as ABA levels. The high-concentration treatments ( $5 \%$ and $7 \%$ ) lowered $A B A$, which can also indirectly enhance fruit set compared with that determined by other chemicals [7].

The leaf $N, P$, and $K$ contents will be reduced with increasing leaf age; by contrast, Ca has the opposite trend, as it will gradually increase, and Mg increases first and then decreases [50]. In accordance with the 
above, the $\mathrm{N}$ content continued to decrease from the blooming stage to the fruiting stage, and the $\mathrm{Ca}$ content continued to increase. $\mathrm{N}$ reached the highest content among all the mineral elements in apple leaves, followed by $\mathrm{Ca}, \mathrm{K}, \mathrm{Mg}$, and $\mathrm{P}$ [51]. Soapberry leaves had the same order of mineral nutrients, so the foliar spraying of apple trees can be a model for soapberry trees. Previous research indicates that $\mathrm{N}$ contents have minimal value in the fruiting stage [52]. After spray application of $3 \%$ sugar, the $\mathrm{N}$ content showed a significant increase when compared with that in the control, which indicates that exogenous sucrose can solve the problem of a low $\mathrm{N}$ content in the fruit abscission stage. $\mathrm{P}$ loss also decreased after spray application of sucrose, while a rapidly decreasing trend was maintained in the control treatment. $\mathrm{K}$ can promote starch transformation to sugar in fruit, and the $\mathrm{K}$ content in the DBFA stage was higher than that in the DBB stage, which could increase the sugar content and yield, so the $\mathrm{K}$ content will be increased after exogenous sucrose application $[53,54]$. The abscission rate of apples decreased after spray treatment with $\mathrm{Ca}$, which reduced the ethylene content [55]. After spray application of sugar in the DBFA stage, the leaf Ca content was lower than that in the blank control, which indicated that fruits (sink) absorbed much more Ca from leaves (source) after exogenous sucrose application than before.

\subsection{Leaf (Source) and Fruit (Sink) Exchange in Response to Different Treatments}

Fruit shoot length was not correlated with the ability of leaves to absorb ${ }^{13} \mathrm{C}$, and previous research also demonstrated that the distance to the source leaves had no effect on fruit growth in the path of transport [56]. It is clear that shoot length cannot influence plant source-sink allocation and transport abilities. This suggests that the shoot-cutting and training method can be used in soapberry pruning, not for nutrient transfer but to regulate apical dominance and light distribution, especially in most soapberry feedstock forests in light-limited areas [21].

There was a weak negative relationship between inflorescence length and the ability of flowers to absorb

${ }^{13} \mathrm{C}$, and shorter and more compact inflorescences had a greater ability to allocate and transport nutrients. Infructescence length was weakly correlated with the fruit absorption ability and exhibited a significant negative relationship with the kernel absorption ability, which demonstrated that the sourcesink transport capacity was determined by kernels. The above is also demonstrated by the fact that Sapindus delavayi has short infructescences, which have a high kernel oil content and high yield [57].

Sucrose is the major photoassimilate transported from photosynthetic leaves to developing fruit, where it is converted into hexose [58]. Walker reported that the rate of sucrose import is regulated by the sucrose concentration gradient between leaves (source) and fruits (sink) and that there is an inverse relationship between import rates and sucrose levels in the fruit. After exogenous sucrose application, the import rates changed, and the sink absorption ability increased, which prevented the formation of a fruit abscission layer.

Endogenous hormones are the signal for carbohydrate transfer from source to sink, especially in the DBFA stage, and the balance between IAA and ABA in leaves and fruit is very important [59]. When 
carbohydrates decrease, ABA will increase rapidly [44]. Positive hormones, such as IAA, ZT and GA, increase in fruits, while ABA decreases, which solves the problem of fruit abscission [60]; this was demonstrated in this study by the fact that ABA in leaves and fruits decreased and IAA increased after spray application of $5 \%$ sucrose.

\subsection{The Direct and Indirect Pathways among Non-Structural Carbohydrates, Endogenous Hormones and Mineral Elements}

The pathways outlined in this study clearly show the positive relationships between fruit sugar and fruit hormones (gibberellins, cytokinins and auxins), and the results of this study are the same as those of previous research indicating that exogenous cytokinins [61] and IAA [62] promoted sucrose accumulation in developing wheat grains. Leaf total sugar was also positively related to leaf cytokinins, leaf nitrogen and fruit $A B A$. This result indicates that if the fruit (sink) absorption ability declines, which will cause the accumulation of leaf total sugar, then fruit ABA will increase, directly leading to fruit drop. Therefore, maintaining a carbohydrate difference between the source and sink can reduce the leaf sugar content and increase the fruit setting rate. Fruit sucrose is directly related to fruit endogenous hormones, the fruit fructose and glucose contents will affect leaf mineral elements, and leaf mineral elements directly affect leaf auxins and sucrose. Leaf total sugar and fruit total sugar are related to leaf $P$, and previous research has indicated that $P$ is involved in the transport of carbohydrates, which play an energy transfer role in the process of sugar alienation $[63,64]$ and participate in the photosynthetic pigment synthesis pathway. $P$ deficiency is related to a reduction in chloroplast carbon fixation as a consequence of photosynthetic potential [65]. Therefore, $\mathrm{P}$ is the main element involved in light acquisition and carbohydrate metabolism and transport [66]. This research demonstrated that the energy transfer between the source and sink mainly relies on $\mathrm{P}$, making this element a key factor for transmission. Leaf $\mathrm{N}$ has a direct correlation with fruit endogenous hormones and leaf total sugar. Leaf $\mathrm{N}$ is an important component of endogenous hormones and is necessary for cell division, which promotes photosynthesis and carbohydrate synthesis, explaining why $L N$ has a direct impact on leaf sugar. Leaf fructose and glucose are correlated with leaf endogenous hormones. ABA stimulates sorbitol oxidase activity to enhance sugar accumulation in the fruit [67]. Fruit total sugar and fruit endogenous hormones are also correlated through leaf fructose, and this mechanism is worthy of further in-depth study.

This study included only the DBB and DBFA stages, and it therefore cannot provide sufficient data to create a pathway for all of the phenological stages. However, these two stages are the most important during the flowering and fruiting stages, and the pathway depicts a clear correlation explaining nutrition transfer from source to sink. Ongoing studies should focus on all phenological stages and more nutrients. Future research will use a molecular genetics approach to define the role of sucrose synthase in fruit development, and long-term studies can be performed to construct a pathway from genetic to physiological control. 


\section{Conclusions}

Fructose, glucose, sucrose, and ZT (cytokinin) levels on the day before blooming were significantly higher than those in the fruit abscission stage. After three exogenous sucrose applications before the blooming stage, there was no significant variation in the leaf TNC content. The carbohydrate content of fruits was $20 \%-70 \%$ higher than that of leaves, which increased the potential of the sink and ensured transport capacity. The 3\% sucrose treatment resulted in a significant (1-1.2-fold) increase in the inflorescence fructose and glucose levels compared to those in the other treatments, and sucrose was $20 \%-40 \%$ higher than in the other treatments. Treatment with $3 \%$ and $5 \%$ sucrose significantly increased fruit $\mathrm{GA}_{3}$ to over $900 \mu \mathrm{g} / \mathrm{g}$ in the DBB stage, and treatment with $3 \%$ sucrose also maintained the largest amounts of L-IAA, F-IAA and F-ZT. The ABA content in leaves decreased from $15 \mu \mathrm{g} / \mathrm{g}$ to $2 \mu \mathrm{g} / \mathrm{g}$ following sucrose application, and the content in the inflorescences decreased from $16 \mu \mathrm{g} / \mathrm{g}$ to $4 \mu \mathrm{g} / \mathrm{g}$, which successfully reduced the stimulation of the flower abscission layer. After three exogenous sucrose applications before the fruit abscission stage, the fructose content in the $1.5 \%$ sucrose treatment was significantly (0.5$1 \mathrm{mg} / \mathrm{g} \mathrm{DW}$ ) higher than that in the other treatments, and the $1.5 \%$ and $3 \%$ treatments significantly increased the glucose and sucrose levels. The $\mathrm{GA}_{3}$ level in the $5 \%$ sucrose treatment increased one-fold greater than that in the control in the DBFA stage, and the control L-IAA level, which was negatively correlated with F-IAA, was much higher than that under all the spraying treatments. Exogenous sucrose decreased the ABA amount in flowers and fruits, reducing F-ABA to $30-50 \%$ of the control level.

Before the blooming stage, $\mathrm{N}$ was detected at the highest percentage, which was over $3 \%$. In the DBFA stage, Ca was present at a higher percentage than the other mineral elements, with a percentage of approximately $6 \pm 1.5 \%$. P showed the lowest content during these two stages. High-concentration sucrose treatment (over $3 \%$ ) increased the $\mathrm{N}, \mathrm{P}$, and $\mathrm{K}$ contents, which decreased the $\mathrm{Ca}$ and $\mathrm{Mg}$ contents. Spray application of sucrose is beneficial for increasing the seed absorption capacity; when the sprayed sucrose concentration was more than $3 \%$ in the DBB stage, the $\mathrm{C}$ dispatching ability of the inflorescence was 3 times greater than that of the leaves. In the DBFA stage, the application of $1.5 \%$ sucrose can guarantee nearly 2 times the allocation capacity from sink to source.

A pathway of source-sink nutrition migration under phosphorus $(P)$ induction was constructed. It showed that leaf sugar and fruit sugar are directly correlated through phosphorus, meaning that $\mathrm{P}$ is the main factor affecting source-to-sink transfer of carbohydrates. Fruit sugar and fruit growth hormones (gibberellins, cytokinins and auxins) are positively correlated; leaf sugar is positively correlated with leaf $\mathrm{ZT}$, leaf $\mathrm{N}$ and $\mathrm{ABA}$. Fruit fructose and glucose contents affect leaf mineral element contents, and leaf mineral elements affect leaf IAA and sucrose directly. Additionally, fruit total sugar and fruit endogenous hormones are correlated via leaf fructose.

\section{Methods}

\subsection{Experimental Site Description and Experimental Materials}


The research site was located in Jianning County, Fujian Province $\left(116^{\circ} 35^{\prime} \sim 117^{\circ} 04^{\prime} \mathrm{E}, 26^{\circ} 30^{\prime} \sim 27^{\circ} 06^{\prime} \mathrm{N}\right)$, where the elevation ranges from 280 to $858 \mathrm{~m}$, the annual average temperature is 16.5 to $17.5^{\circ} \mathrm{C}$, the average rainfall is $1800 \mathrm{~mm}-2100 \mathrm{~mm}$, the average sunshine duration is $1721 \mathrm{~h}$ per year and the relative humidity is $84 \%[3,21]$. The soil parent material is feldspar sandstone, and the soil texture is mostly heavy loam (Cartesian) to light clay (soil layer thickness $>100 \mathrm{~cm}$ ) $[68,69]$.

The experimental forest (approximately 5200 ha) was planted by Yuan Hua Forestry Biotechnology Co. in 2008. The experimental plot was located in the Fengyuan Demonstration Zone. The study trees were planted in 2009 with 2-year-old nursery stock, which came from Tiantai, Zhejiang Province, using level terraces, and the planting density was 675-750 plants/ha. Management measures included pruning once per year, fertilization once per year, and disease and insect pest prevention 3-5 times per year.

Thirty healthy trees that had 3 scaffold branches with an angle of $60^{\circ}$ and $16-18$ fruiting branches per unit area that had grown for 8 years were selected. The planting holes were $50 \times 40 \times 40 \mathrm{~cm}$, the plant spacing was $4 \times 4 \mathrm{~m}$, the tree height was $5.9 \pm 0.64 \mathrm{~m}$, the tree basal diameter was $16.14 \pm 0.51 \mathrm{~cm}$, and the tree crown width was $4.2 \pm 0.66 \mathrm{~m}$.

\subsection{Field Experimental Measurements}

\subsubsection{Spraying Treatments, ${ }^{13} \mathrm{C}$ Labelling and Sampling}

This experiment was conducted to evaluate the effects of exogenous sucrose application at two stages: 20 days before blooming (DBB stage) and the second fruit abscission stage (DBFA stage); the dates of these two stages were defined according to the research of Gao et al. [3] from 2013-2015. The blooming stage began on $18^{\text {th }}$ May \pm 2 days, and the abscission stage began on $28^{\text {th }}$ August \pm 2 days (Fig. 8). Sucrose solutions of 6 different concentrations, $0 \%$ (control), $1 \%, 1.5 \%, 3 \%, 5 \%$ and $7 \%$, were applied by spraying three times every seven days $[7,70]$ until 5 days before blooming and abscission, for a total of 6 times during these two different stages. The experiment was conducted with a completely randomized block design with 5 replications ( $n=$ one tree per replicate) and 6 treatments. Each tree was sprayed with 5 $\mathrm{L}$ of water containing dissolved sucrose, which made the surface wet to the point of dripping. The experiment was carried out under temperatures of 27 and $21^{\circ} \mathrm{C}$ (maximum and minimum, respectively), and the light ratio percentage under the canopy was in the range of approximately $30-40 \%$. The samples were randomly selected; 8 soapberry inflorescences and infructescences from outer branches growing in different directions at the middle-canopy height were selected from each treatment after 7 days of spraying. The leaves were selected from the 4th-8th leaf positions from the shoot tip.

${ }^{13} \mathrm{CO}_{2}$ labelling experiments were carried out under sunny conditions from 11:00 to 13:00 after 3 sprayings during the two stages. Four inflorescences and infructescences were selected from branches 
with different orientations for each treatment group at the middle-canopy height for ${ }^{13} \mathrm{C}$ labelling. Transparent polyethylene $(\mathrm{PE})$ plastic bags $(40 \times 50 \mathrm{~cm})$ were used to cover the inflorescences and infructescences.

Twenty millilitres of ${ }^{13} \mathrm{CO}_{2}$ (99 atom\%) (purchased from SRICl) was injected into the bags every hour a total of 4 times to maintain the ${ }^{13} \mathrm{CO}_{2}$ density at $500 \mu \mathrm{mol} / \mathrm{mol}$. The samples were taken $24,48,72$ and $96 \mathrm{~h}$ after ${ }^{13} \mathrm{C}$ isotope labelling; 5 soapberry leaves, flowers or fruits were randomly selected from the labelled inflorescences and infructescences. The consumption trends in these four samples were compared for the same time periods, and there was no significant consumption at $96 \mathrm{~h}$, so 24 and $48 \mathrm{~h}$ were chosen for analysis of the results.

All sampled material was converted to $\mathrm{CO}_{2}$ and then analysed for $\delta 13 \mathrm{C}$ by isotope ratio mass spectrometry (DELTA V Advantage) with an accuracy better than $0.1 \%$, which was performed by Thermo Fisher Scientific, Inc., USA. ${ }^{13} \mathrm{C}(\mathrm{mg} / \mathrm{g})$ was calculated by the formula below:

${ }^{13} \mathrm{C}(\mathrm{mg} / \mathrm{g})=\mathrm{m}_{\mathrm{DW}}{ }^{\star} \mathrm{C} \%{ }^{*}\left(\right.$ Atom $\%{ }^{13} \mathrm{C}_{\text {labelled }}{ }^{-}$Atom $\left.\%{ }^{13} \mathrm{C}_{\text {unlabelled }}\right)[71]$.

\subsubsection{Determination of Sucrose, Glucose and Fructose}

One-gram samples were dissolved in $5 \mathrm{~mL}$ of ultra-pure water and subjected to ultrasonic bath extraction for $10 \mathrm{~min}$. The samples were centrifuged for $10 \mathrm{~min}$ at $12000 \mathrm{r} / \mathrm{min}$ and $4^{\circ} \mathrm{C}$ and then filtered through $0.45-\mu \mathrm{m}$ hydrophobic membranes.

The concentrations of sucrose, glucose, and fructose were quantified by high-performance liquid chromatography (HPLC). An Agilent Zorbax carbohydrate column $(4.6 \times 150 \mathrm{~mm}, 5 \mu \mathrm{m})$ was used for the analysis and kept at $35^{\circ} \mathrm{C}$. The mobile phase was $80 \%$ acetonitrile $+20 \%$ ultra-pure water. The sample injection volume was $10 \mu \mathrm{l}$, the flow velocity was $1 \mathrm{~mL} / \mathrm{min}$, and the injection time was $17 \mathrm{~min}$. Prior to carrying out the determination of TNCs in the sample, standard solutions of sucrose, fructose and glucose were prepared. Calibration curves were made for each of the sugars using these solutions $[34,72$, 73].

\subsubsection{Determination of Endogenous Hormones}

In this study, extraction of plant hormones was performed by HPLC as previously described [74, 75], with some modifications as detailed below. Approximately $1 \mathrm{~g}$ of fresh leaves was frozen in liquid nitrogen and ground into powder. Five millilitres of $80 \%$ ice-methanol $\left(4^{\circ} \mathrm{C}\right.$, kept in the dark) was used to soak the samples for $10 \mathrm{~h}$. Then, the samples were centrifuged at $12000 \mathrm{r} / \mathrm{min}$ at $4^{\circ} \mathrm{C}$ for $30 \mathrm{~min}$ and transferred to a bottle, to which 1-2 drops of ammonium hydroxide were added. The bottles were rotary evaporated at 
$38^{\circ} \mathrm{C}$ until reaching $1 / 3$ of their original volume. Then, $2 \mathrm{~mL}$ of distilled water was used to wash the samples into 10-mL tubes; the samples were centrifuged at $12000 \mathrm{r} / \mathrm{min}$ at $4^{\circ} \mathrm{C}$ for $30 \mathrm{~min}$ again and adjusted to a pH of 2.5-3.0 (for IAA, gibberellic acid (GA ${ }_{3}$ ) and ABA) or 7.5-8.0 (for ZT). IAA, GA 3 and ABA were extracted by ethyl acetate, ZT was extracted by water-saturated n-butyl alcohol, and the extractions were repeated 3 times. The samples were rotary evaporated to dryness and finally dissolved in $1 \mathrm{~mL}$ of methanol- $0.1 \mathrm{~mol} / \mathrm{L}$ acetic acid (1:4, v/v), except for ZT, which was dissolved in $3 \%$ methanol- $97 \%$ ultrapure water with a $\mathrm{pH}=7$. Prior to HPLC analysis, the solution was filtered using a $0.45-\mu \mathrm{m}$ microfilter. A 4.6 $\times 250$-mm 5-micron Zorbax EclipsexDB-C18 analytical column was used for analysis, with a sample injection volume of $5 \mu \mathrm{L}$, a flow velocity of $1 \mathrm{~mL} / \mathrm{min}$, and a temperature of $30^{\circ} \mathrm{C}$. The mobile phase for IAA, $\mathrm{GA}_{3}$ and $A B A$ was $20 \%$ methanol $+80 \% 1 \mathrm{~N}$ acetic acid and for $\mathrm{ZT}$ was $40 \%$ methanol $+60 \%$ ultra-pure water with a $\mathrm{pH}=7$.

\subsubsection{Determination of Mineral Elements}

The leaves were cleaned, separated, and dried in a $70^{\circ} \mathrm{C}$ oven, and the dry plant samples were ground and analysed for their nutrient contents $(\mathrm{N}, \mathrm{P}$, and $\mathrm{K}) . \mathrm{H}_{2} \mathrm{SO}_{4}-\mathrm{H}_{2} \mathrm{O}_{2}$ was used for digestion, and then the $\mathrm{N}$ (total nitrogen), $\mathrm{P}$ (total phosphorus), and $\mathrm{K}$ (total potassium) concentrations were measured using a Kjeldahl nitrogen meter (Beijing, China), the vanadium molybdenum yellow colorimetric method, and flame photometry, respectively [76]. Samples were wet digested in a mixture of nitric acid-perchloric acid $\left(\mathrm{HNO}_{3}: \mathrm{HClO}_{4}(4: 1)\right.$, and the $\mathrm{K}, \mathrm{Ca}$, and $\mathrm{Mg}$ concentrations in the digest were quantified by atomic absorption spectrophotometry (Varian Model Spectra-400 Plus) [77].

\subsection{Data Analysis}

The data were statistically analysed using Student's t-test $(P<0.05)$. Five biological replicates were used in the TNC, endogenous hormone, and mineral element analyses, and data were analysed with SPSS Statistics 20.0 software (SPSS Inc., Chicago, IL, USA) at the $P \leq 0.05$ significance level using Duncan's multiple range test. To identify significant differences, repeated measurements were statistically compared between the treatments using one-way analysis of variance (ANOVA). Correlation and linear regression analyses were performed to identify and evaluate the relationships among the lengths of shoots, inflorescences, and infructescences and the ${ }^{13} \mathrm{C}$ content of leaves, fruits and seeds.

The relationships between fruit and leaf nutrients were investigated using canonical correlation analysis (CCA). Five groups were created (1. Leaf sugar: LS, LG, and LF; 2. Fruit sugar: FS, FG, and FF; 3. Leaf hormones: L-GA 3 , L-IAA, L-ABA, and L-ZT; 4. Fruit hormones: F-GA, F-IAA, F-ABA, and F-ZT; and 5. Leaf mineral elements: $L N, L P, L K, L C a$, and $L M g$ ) to examine the correlation between a linear combination of the fruit nutrient variables (X-set), designated canonical variable $U$, and a linear combination of the leaf nutrient variables (Y-set), designated canonical variable V. All the data were standardized. Ten repeated 
comparisons were used in the analysis. All computations used to examine the relationships between the two sets of traits were performed with R software [78, 79]. Excel 2016 and Origin 2017 were used to create the charts.

\section{Abbreviations}

DBB, days before blooming; DBFA, days before fruit abscission; FAR, fruit abscission rate (\%); HPLC, highperformance liquid chromatography; $L F$, leaf fructose (mg/(g DW)); $F F$, fruit fructose $(\mathrm{mg} /(\mathrm{g} \mathrm{DW}))$; $L G$, leaf glucose $(\mathrm{mg} /(\mathrm{g} D W)) ; F G$, fruit glucose $(\mathrm{mg} /(\mathrm{g} \mathrm{DW}))$; LS, leaf sucrose $(\mathrm{mg} /(\mathrm{g} \mathrm{DW})) ; \mathrm{FS}$, fruit sucrose $(\mathrm{mg} /(\mathrm{g} \mathrm{DW})) ; \mathrm{IAA}$, indole acetic acid $(\mu \mathrm{g} / \mathrm{g}) ; A B A$, abscisic acid $(\mu \mathrm{g} / \mathrm{g}) ; \mathrm{GA}_{3}$, gibberellic acid $(\mu \mathrm{g} / \mathrm{g}) ; \mathrm{ZT}$, zeatin $(\mu \mathrm{g} / \mathrm{g})$; N, nitrogen (\%); P, phosphorus (\%); K, potassium (\%); Ca, calcium (\%); Mg, magnesium (\%); TNC, non-structural carbohydrate

\section{Declarations}

\section{Ethics Approval and Consent to Participate}

Not applicable

\section{Consent for Publication}

Not applicable

\section{Availability of Data and Materials}

The datasets generated and analysed during the current study are not publicly available due to the raw data were measured by our research team which forms a part of an ongoing study, but are available from the corresponding author on reasonable request.

\section{Competing Interests}

The authors declare that they have no competing interests

\section{Funding}

This research was jointly supported by the Fundamental Research Funds for the Central Universities of China (2015ZCQ-LX-02) and the International S\&T Cooperation Program of China (2014DFA31140). 


\section{Authors' Contributions}

Writing, original draft, review and editing, Yuan Gao and Liming Jia; methodology and equipment determination, Yuan Gao, Ying Yang and Shiqi Liu; formal analysis and investigation, Yuan Gao and Shilun Gao; supervision and funding acquisition, Liming Jia and Xuehuang Weng.

\section{Acknowledgements}

We are grateful to the team of Yuan Hua Forestry Biotechnology Co., Ltd., for providing the forestry materials and assistance. Thanks to Prof. Benye Xi of Beijing Forestry University, who provided guidance in graph design. We would also like to thank the other members of our working group and the support of Chinese Scholarship Council and the IBM 100 Young Big Data Scientists Cooperation Program (Y-100).

\section{References}

1. Jia L, Sun C. Research progress of biodiesel tree Sapindus mukorossi. J China Agric Univ. 2012;17:191-6.

2. State Forestry Administration. The planning of National forestry biomass energy development (2011-2020). Beijing: Forest Plan Development; 2013.

3. Gao Y, Jia LM, Su SC, Dai L, Weng Z, Guo Y, et al. Phenology and blossom-fruiting characteristics of Sapindus mukorossi. J Northeast For Univ. 2015;43:34-40.

4. Sánchez-Torres P, González-Candelas L. Isolation and characterization of genes differentially expressed during the interaction between apple fruit and Penicillium expansum. Mol Plant Pathol. 2003;4:447-57.

5. Mitra SK, Pereira LS, Pathak PK, Majumadar D. Fruit abscission pattern of lychee cultivars. Acta Hortic. 2005;665:215-8.

6. Janssen BJ, Thodey K, Schaffer RJ, Alba R, Balakrishnan L, Bishop R, et al. Global gene expression analysis of apple fruit development from the floral bud to ripe fruit. BMC Plant Biol. 2008;8:16.

7. Gill J, Dhillon W, Gill P, Singh N. Fruit set and quality improvement studies on semi-soft pear cv. Punjab beauty. Indian J Hortic. 2012;69:39-44.

8. Mostafa $\mathrm{E}$, Saleh M, Abdel-Migeed M. Improving Leconte pear trees productivity by spraying $\mathrm{GA}_{3}$ and sucrose. Arab Univ J Agric Sci. 2001;9:373-95.

9. Iglesias DJ, Tadeo FR, Primo-Millo E, Talon M. Fruit set dependence on carbohydrate availability in citrus trees. Tree Physiol. 2003;23:199-204. 
10. Hagen KS, Dadd RH, Reese J. The food of insects. In: Huffaker CB, Rabb RL, editors. Ecological entomology. New York, NY: Wiley; 1984. p. 79-112.

11. Rogers ME, Potter DA. Potential for sugar sprays and flowering plants to increase parasitism of white grubs (Coleoptera: Scarabaeidae) by Tiphiid wasps (Hymenoptera: Tiphiidae). Environ Entomol. 2004;33:619-26.

12. Du L, Qi S, Ma J, Xing L, Fan S, Zhang S, et al. Identification of TPS family members in apple (Malus $x$ domestica Borkh.) and the effect of sucrose sprays on TPS expression and floral induction. Plant Physiol Biochem. 2017;120:10-23.

13. Ulrich L. Physiological ecology section. Bull Ecol Soc Am. 2007;88:360-1.

14. Eccher G, Botton A, Dimauro M, Boschetti A, Ruperti B, Ramina A. Early induction of apple fruitlet abscission is characterized by an increase of both isoprene emission and abscisic acid content. Plant Physiol. 2013;161:1952-69.

15. Turgeon R. The puzzle of phloem pressure. Plant Physiol. 2010;154:578-81.

16. Ainsworth EA, Bush DR. Carbohydrate export from the leaf: a highly regulated process and target to enhance photosynthesis and productivity. Plant Physiol. 2011;155:64-9.

17. Xu YL, Tan L, Guo L, Yang GL, Li Q, Lai F, et al. Increasing starch productivity of Spirodela polyrhiza by precisely control the spectral composition and nutrients status. Ind Crops Prod. 2019;134:284-91.

18. Deng L, Pan X, Chen L, Shen L, Sheng J. Effects of preharvest nitric oxide treatment on ethylene biosynthesis and soluble sugars metabolism in 'Golden Delicious' apples. Postharvest Biol Technol. 2013;84:9-15.

19. Berrie AMM. The effect of sucrose sprays on the growth of tomato. Physiol Plant. 1960;13:9-19.

20. Wójcik P, Akgül H, Demirtaş İ, Sarısu C, Aksu M, Gubbuk H. Effect of preharvest sprays of calcium chloride and sucrose on cracking and quality of 'burlat' sweet cherry fruit. J Plant Nutr. 2013;36:145365.

21. Gao Y, Gao S, Jia L, Dai T, Wei X, Duan J, et al. Canopy characteristics and light distribution in Sapindus mukorossi Gaertn. are influenced by crown architecture manipulation in the hilly terrain of Southeast China. Sci Hortic. 2018;240:11-22.

22. Amiri NA, Arzani K, Kangarshahi AA. Reduction in june drop, a way to reduce losses of satsuma mandarin (Citrus unshiu). Acta Hortic. 2012;928:287-90.

23. Smoleń S, Sady W. Effect of foliar application of urea, molybdenum, benzyladenine, sucrose and salicylic acid on yield, nitrogen metabolism of radish plants and quality of edible roots. J Plant Nutr. 2012;35:1113-29.

24. Cheng L, Ma F, Ranwala D. Nitrogen storage and its interaction with carbohydrates of young apple trees in response to nitrogen supply. Tree Physiol. 2004;24:91-8.

25. Morcuende R, Krapp A, Hurry V, Stitt M. Sucrose-feeding leads to increased rates of nitrate assimilation, increased rates of a-oxoglutarate synthesis, and increased synthesis of a wide spectrum of amino acids in tobacco leaves. Planta. 1998;206:394-409. 
26. Loescher WH, Marlow GC, Kennedy RA. Sorbitol metabolism and sink-source interconversions in developing apple leaves. Plant Physiol. 1982;70:335-9.

27. Kozlowski TT. Carbohydrate sources and sinks in woody plants. Bot Rev. 1992;58:107-222.

28. Rolland F, Baena-Gonzalez E, Sheen J. Sugar sensing and signaling in plants: conserved and novel mechanisms. Ann RevPlant Biol. 2006;57:675-709.

29. Cannell MGR. Growth control in woody plants. Tree Physiol. 1997;17:489.

30. Domingos S, Scafidi P, Cardoso V, Leitao AE, di Lorenzo R, Oliveira CM, et al. Flower abscission in Vitis vinifera $\mathrm{L}$. triggered by gibberellic acid and shade discloses differences in the underlying metabolic pathways. Front Plant Sci. 2015;6:18.

31. Cakmak I, Marschner H, Bangerth F. Effect of zinc nutritional status on growth, protein metabolism and levels of indole-3-acetic acid and other phytohormones in bean (Phaseolus vulgaris L.). J Exp Bot. 1989;40:405-12.

32. Sekimoto H, Hoshi M, Nomura T, Yokota T. Zinc deficiency affects the levels of endogenous gibberellins in Zea mays L. Plant Cell Physiol. 1997;38:1087-90.

33. Liu L, Cang J, Yu J, Wang X, Huang R, Wang J, et al. Effects of exogenous abscisic acid on carbohydrate metabolism and the expression levels of correlative key enzymes in winter wheat under low temperature. Biosci Biotechnol Biochem. 2013;77:516-25.

34. Javid MG, Sorooshzadeh A, Sanavy SAMM, Allahdadi I, Moradi F. Effects of the exogenous application of auxin and cytokinin on carbohydrate accumulation in grains of rice under salt stress. Plant Growth Regul. 2011;65:305-13.

35. Brenner ML, Cheikh N. The role of hormones in photosynthate partitioning and seed filling. In: Davies PJ, editor. Plant hormones: physiology, biochemistry and molecular biology. Dordrecht: Springer; 1995. p. 649-70.

36. Gosnell J. Some factors affecting flowering in sugarcane. Proc S Afr Sugar Technol Assoc. 1973;47:144-7.

37. Brunkhorst MJ. A preliminary investigation into the effect of plant nutrient levels on sugarcane flowering. Proc S Afr Sugar Technol Ass. 2001;75:143-50.

38. Bell Cl, Leigh RA. Differential effects of turgor on sucrose and potassium transport at the tonoplast and plasma membrane of sugar beet storage root tissue. Plant Cell Environ. 1996;19:191-200.

39. Endres L, da Cruz SJS, Vilela RD, dos Santos JM, Barbosa GVS, Silva JAC. Foliar applications of calcium reduce and delay sugarcane flowering. BioEnergy Res. 2015;9:98-108.

40. Bi G, Scagel CF, Cheng L, Fuchigami LH. Soil and foliar nitrogen supply affects the composition of nitrogen and carbohydrates in young almond trees. J Hortic Sci Biotechnol. 2004;79:175-81.

41. Lobo AKM, de Oliveira Martins M, Neto MCL, Machado EC, Ribeiro RV, Silveira JAG. Exogenous sucrose supply changes sugar metabolism and reduces photosynthesis of sugarcane through the down-regulation of rubisco abundance and activity. J Plant Physiol. 2015;179:113-21. 
42. Saadati S, Moallemi N, Mortazavi SMH, Seyyednejad SM. Effects of zinc and boron foliar application on soluble carbohydrate and oil contents of three olive cultivars during fruit ripening. Sci Hortic. 2013;164:30-4.

43. Nagy PT, Thurzó S, Szabo Z, Nyeki J, Silva AP, Gonçalves B. Influence of foliar fertilization on mineral composition, sugar and organic acid content of sweet cherry. Acta Hortic. 2010;868:353-8.

44. Gómez-Cadenas A, Mehouachi J, Tadeo FR, Primo-Millo E, Talon M. Hormonal regulation of fruitlet abscission induced by carbohydrate shortage in citrus. Planta. 2000;210:636-43.

45. Ülger S, Atmaca S, Demiral S. The effects of $\mathrm{GA}_{3}$ treatment on yield, carbohydrate, and endogenous hormone changes in Memecik olive cultivar. Turk J Agric For. 2018;42:75-81.

46. Botton A, Eccher G, Forcato C, Ferrarini A, Begheldo M, Zermiani M, et al. Signaling pathways mediating the induction of apple fruitlet abscission. Plant Physiol. 2011;155:185-208.

47. Glozer K, Grant JA. Effects of fall applications of urea and zinc sulfate tobing'sweet cherry spring budbreak. Hortic Sci. 2006;41:1030-1.

48. Gibson SI. Sugar and phytohormone response pathways: navigating a signalling network. J Exp Bot. 2004;55:253-64.

49. Talon M, Tadeo FR, Ben-Cheikh W, Gomez-Cadenas A, Mehouachi J, PeÂrez-Botella J, et al. Hormonal regulation of fruit set and abscission in citrus: classical concepts and new evidence. Acta Hortic. 1998;463:209-18.

50. Lin M. Study on changes and correlations of nutrient material concentration in leaves and fruits of whangkeumbae. MS Thesis, Agricultural University of Hebei; 2005.

51. Li G, Su R, Shen J. The research of several kinds of deciduous fruit trees' leaf mineral element content standard values. Acta Hortic Sin. 1989;81-9.

52. Fernández-Escobar R, Moreno R, García-Creus M. Seasonal changes of mineral nutrients in olive leaves during the alternate-bearing cycle. Sci Hortic. 1999;82:25-45.

53. Huang $X$, Wang $Q$, Zhao T. Effects of potassium fertilizers for improving quality and production of fruit crops. Fruits Sci 2000;17:309-13.

54. Qu G, Shu H, Wang H. Potassium influence the related parameters of apple tree water use efficiency. Acta Pedol Sin. 2000;257-62.

55. Guan J, Shu H, Huang T. The effect of calcium on ethylene production of'starkrimson'apple. Acta Hortic Sin. 1991;18:205-9.

56. Garcia-Luis A, Oliveira MEM, Bordon Y, Siqueira DL, Tominaga S, Guardiola JL. Dry matter accumulation in citrus fruit is not limited by transport capacity of the pedicel. Ann Bot. 2002;90:75564.

57. Sun C, Jia L, Xi B, Wang L, Weng X. Natural variation in fatty acid composition of Sapindus spp. seed oils. Ind Crops Prod. 2017;102:97-104.

58. Walker AJ, Ho LC. Carbon translocation in the tomato: effects of fruit temperature on carbon metabolism and the rate of translocation. Ann Bot. 1977;41:825-32. 
59. Cooper WC, Henry WH. Effect of growth regulators on the response of citrus fruit to cycloheximide induced abscission. Proc Fla State Hortic Soc. 1972;85:29-32.

60. Gao Q. Study on the growth and development of the fruitlet and the content changes of mineral element and endo-hormone in almod. MS Thesis. China: Xinjiang Agricultural University; 2006.

61. Asthir B, Kaur A, Basra AS. Do phytohormones influence the uptake and metabolism of sucrose in spikelets of wheat? Phyton Horn. 1998;38:293-9.

62. Darussalam CMA, Patrick JW. Auxin control of photoassimilate transport to and within developing grains of wheat. Funct Plant Biol. 1998;25:69-78.

63. Vance CP, Uhde-Stone C, Allan DL. Phosphorus acquisition and use: critical adaptations by plants for securing a nonrenewable resource. New Phytol. 2003;157:423-47.

64. Wang D. Seasonal changes of mineral elements in leaves of Pistacia chinensis in Chongqing. MS Thesis. Chongqing: Southwest University; 2012.

65. Chrysargyris A, Panayiotou C, Tzortzakis N. Nitrogen and phosphorus levels affected plant growth, essential oil composition and antioxidant status of lavender plant (Lavandula angustifolia Mill.). Ind Crops Prod. 2016;83:577-86.

66. Xiao L, Wang S. Plant physiology. Beijing: China Agricultural Press; 2004.

67. Kobashi K, Gemma H, Iwahori S. Sugar accumulation in peach fruit as affected by abscisic acid (ABA) treatment in relation to some sugar metabolizing enzymes. J Jpn Soc Hortic Sci. 1999;68:46570.

68. Li XQ. Introduction of technology of Sapindus mukorossi in Jianning. Green Sci Technol. 2013;11:445.

69. Ding F. Studies on fertilizer formula for young sapindus. MS Thesis, Nanjing Forestry University; 2014.

70. Awasthi SP, Narayana HS. Effect of sucrose and sucrose plus boric acid spray on nodulation of Trigonella foenumgraecum. Comp Physiol Ecol. 1984;9:36-7.

71. Zhou Y, Qin S, Ma X, Zhang J, Zhou P, Sun M, et al. Effect of interstocks on the photosynthetic characteristics and carbon distribution of young apple trees during the vigorous growth period of shoots. Eur J Hortic Sci. 2015;80:296-305.

72. Ulger S, Sonmez S, Karkacier M, Ertoy N, Akdesir O, Aksu M. Determination of endogenous hormones, sugars and mineral nutrition levels during the induction, initiation and differentiation stage and their effects on flower formation in olive. Plant Growth Regul. 2004;42:89-95.

73. Yuan L, Zhu S, Li S, Shu S, Sun J, Guo S. 24-epibrassinolide regulates carbohydrate metabolism and increases polyamine content in cucumber exposed to $\mathrm{Ca}\left(\mathrm{NO}_{3}\right)_{2}$ stress. Acta Physiol Plant. 2014;36:2845-52.

74. Zeng Q, Chen HB, Lu CH, Li JG. An optimized HPLC procedure for analyzing endogenous hormones in different organs of litchi. J Fruit Sci. 2006;23:145-8. 
75. Pan X, Welti R, Wang X. Simultaneous quantification of major phytohormones and related compounds in crude plant extracts by liquid chromatography-electrospray tandem mass spectrometry. Phytochemistry. 2008;69:1773-81.

76. Bao SD. Soil agro-chemistrical analysis. Beijing, China: China Agriculture Press; 2007.

77. Kacar B. Chemical analyses of plant and soil. II bitki analizleri. Agricultural Faculty Publications: 453, aplication guide: 155. Ankara: University of Ankara Basmevi; 1972.

78. Gunderson BK, Muirhead RJ. On estimating the dimensionality in canonical correlation analysis. J Multivar Anal. 1997;62:121-36.

79. Cankaya S, Balkaya A, Karaagac O. Canonical correlation analysis for the determination of relationships between plant characters and yield components in red pepper (Capsicum annuum $\mathrm{L}$. var. conoides (Mill.) Irish) genotypes. Span J Agric Res. 2010;8:67-73.

\section{Figures}

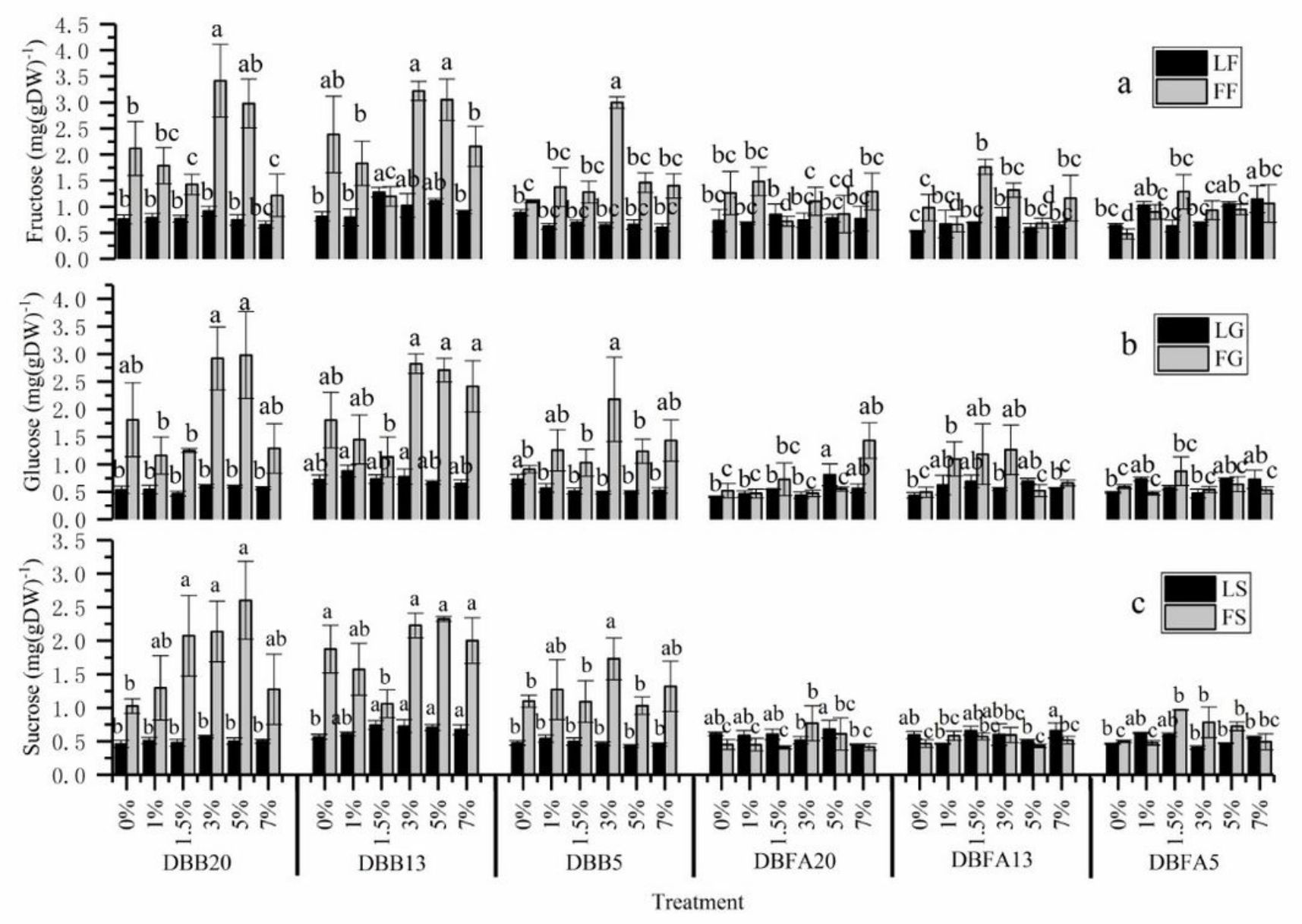

Figure 1 
Comparison of non-structural carbohydrates after exogenous sucrose application 20, 13 and 5 days before the blooming stage and fruit abscission stage. (a) the amount of fructose in leaves and fruits under the 6 exogenous sugar application treatments; (b) the amount of glucose in leaves and fruits under the 6 exogenous sugar application treatments; (c) the amount of sucrose in leaves and fruits under the 6 exogenous sugar application treatments. Vertical bars indicate standard errors. Different letters above bars indicate significant differences between treatments based on Duncan's multiple range test at a $p$ value $<0.05$. DW indicates dry weight.
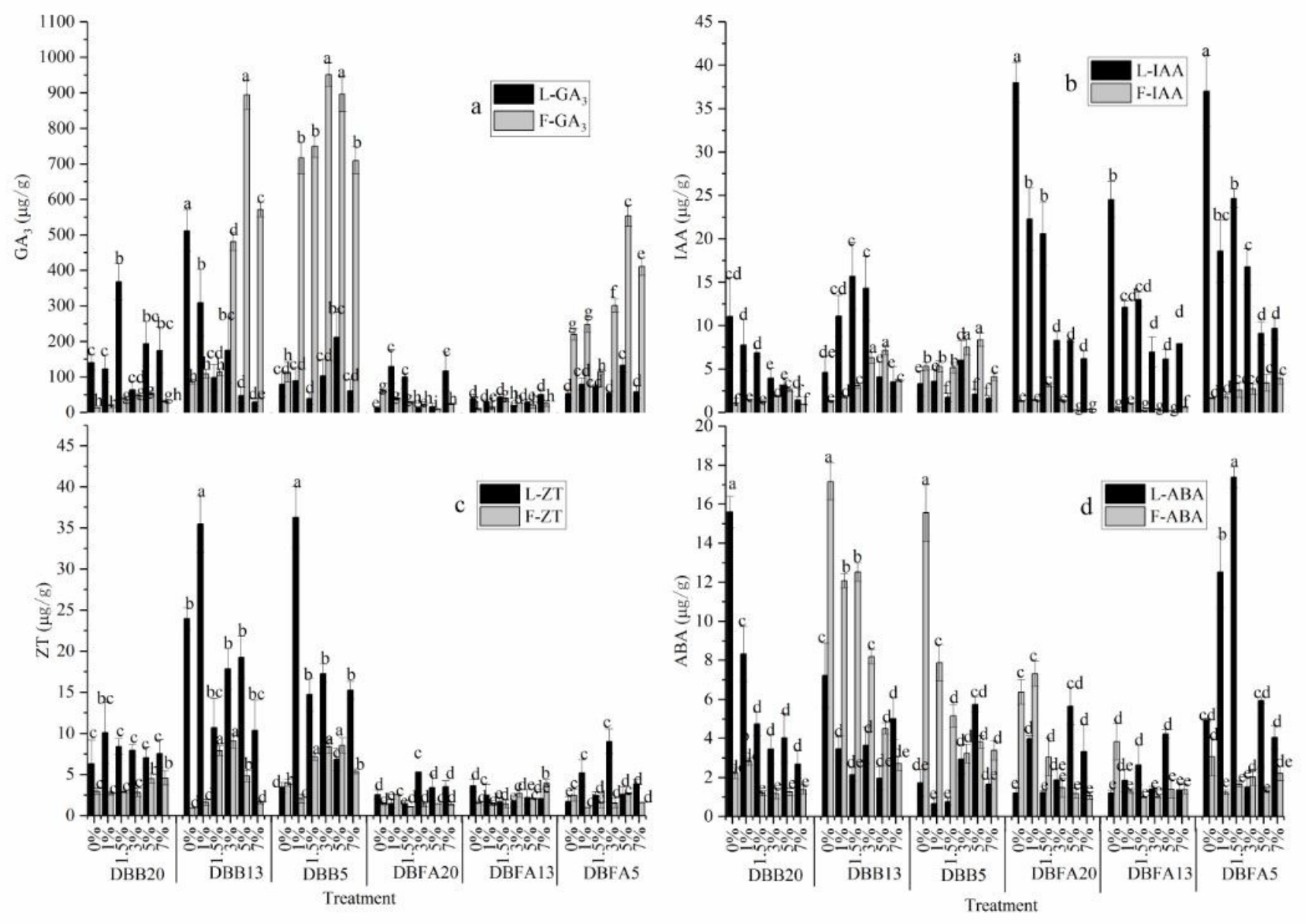

\section{Figure 2}

Comparison of endogenous hormone contents after exogenous sucrose application 20, 13 and 5 days before the blooming stage and fruit abscission stage. (a) The amount of GA3 in leaves and fruits under the 6 exogenous sucrose treatments; (b) the amount of IAA in leaves and fruits under the 6 exogenous sucrose treatments; (c) the amount of ZT in leaves and fruits under the 6 exogenous sucrose treatments; (d) the amount of ABA in leaves and fruits under the 6 exogenous sucrose treatments. Vertical bars indicate standard errors. Different letters above the bars indicate significant differences between treatments based on Duncan's multiple range test at a $p$-value $<0.05$. 

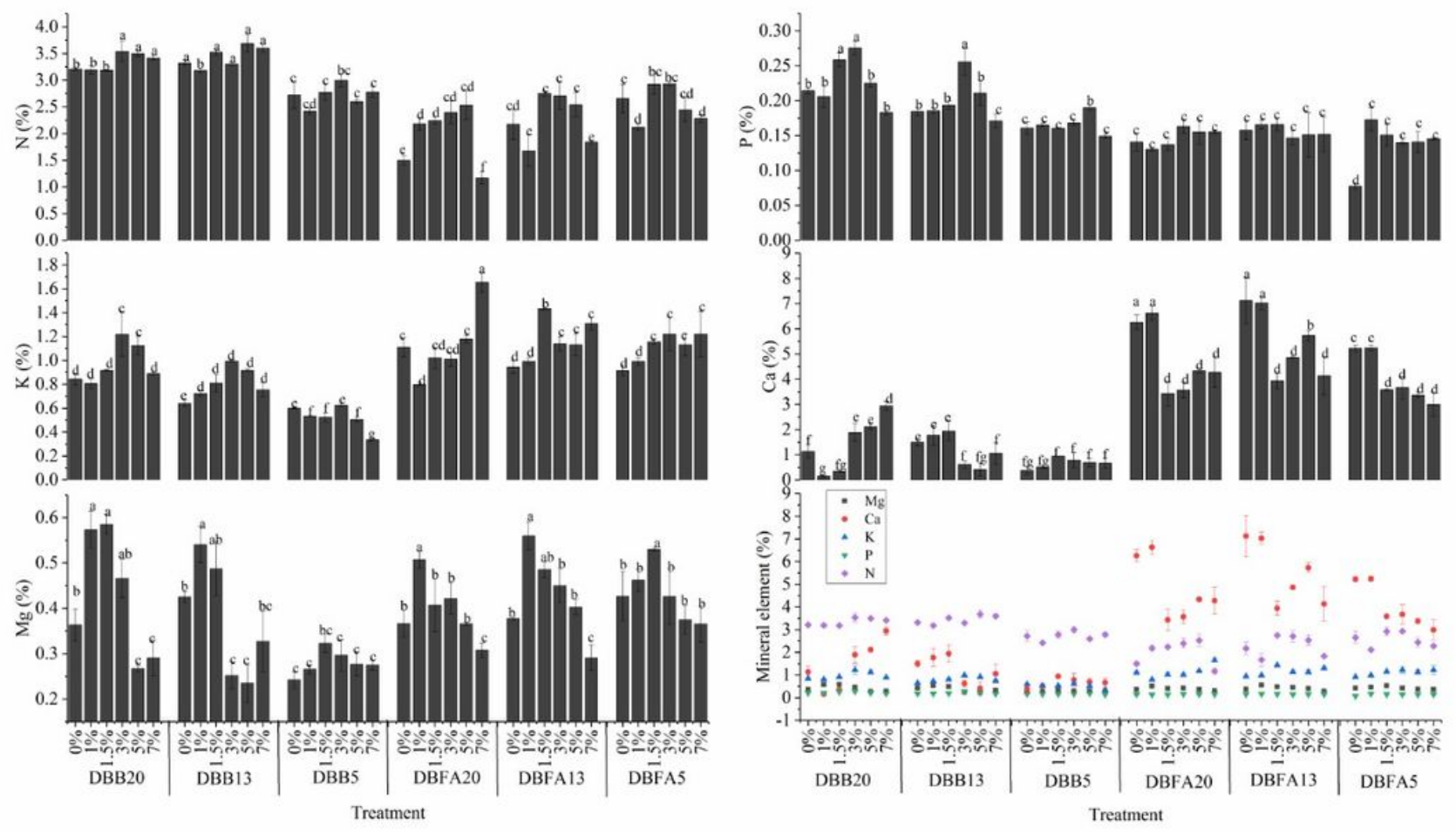

Figure 3

Comparison of mineral elements after exogenous sucrose application 20, 13 and 5 days before the blooming stage and fruit abscission stage. The amounts of $\mathrm{N}, \mathrm{P}, \mathrm{K}, \mathrm{Ga}$, and $\mathrm{Mg}$ in leaves under 6 exogenous sucrose treatments are shown in the five figures, respectively, and the last figure compares these 5 mineral elements. Vertical bars indicate standard errors. Different letters above the bars indicate significant differences between treatments based on Duncan's multiple range test at a $p$-value $<0.05$. 

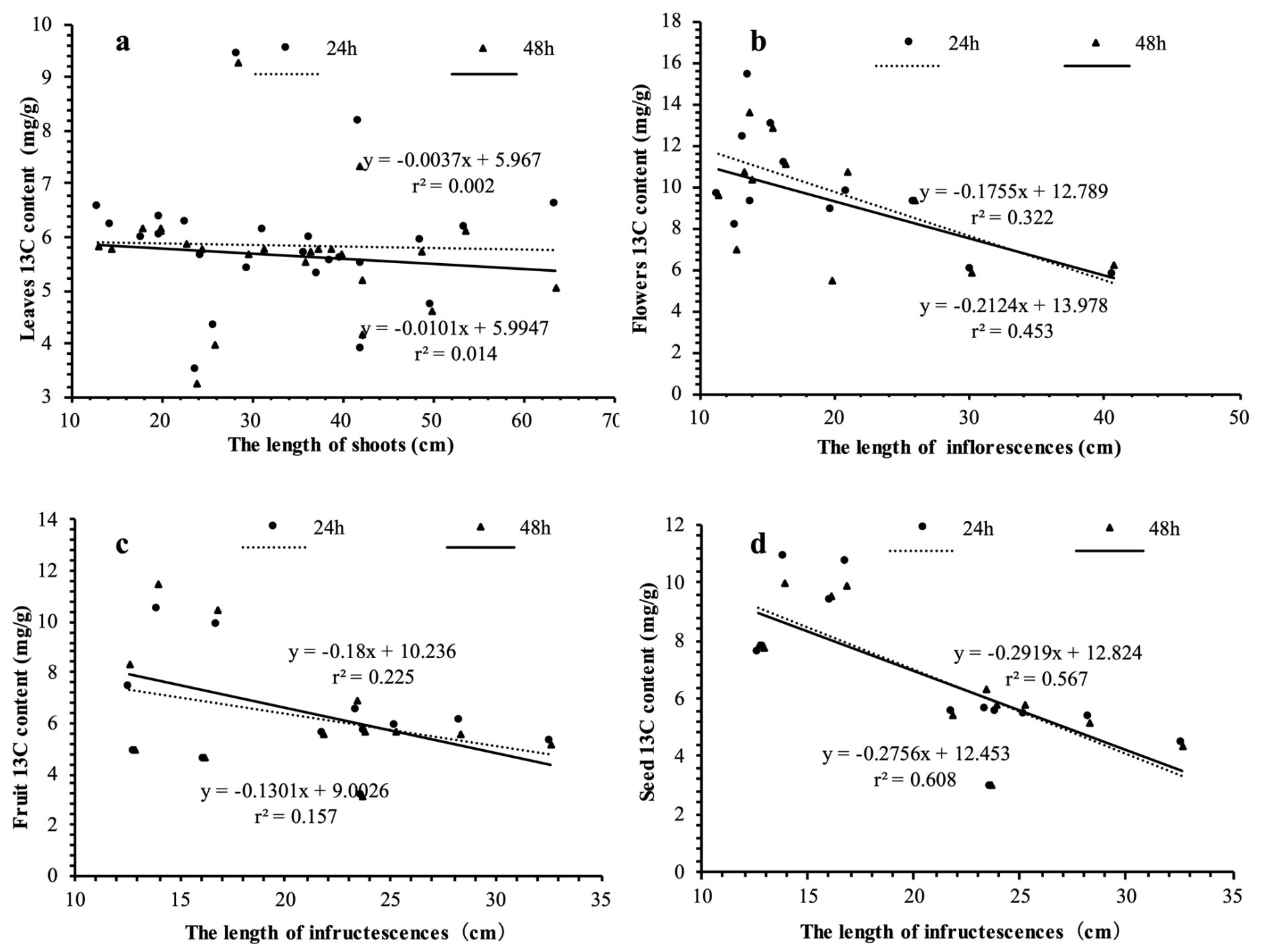

Figure 4

The relation between $13 \mathrm{C}$ values and the lengths of shoots, inflorescences and infructescences after $24 \mathrm{~h}$ and $48 \mathrm{~h}$ of isotope labelling. (a) The relationship between the length of shoots and leaf $13 \mathrm{C}$ content. (b) The relationship between the length of inflorescences and flower $13 \mathrm{C}$ content. (c) The relationship between the length of infructescences and fruit $13 \mathrm{C}$ content. (d) The relationship between the length of infructescences and seed $13 \mathrm{C}$ content. 

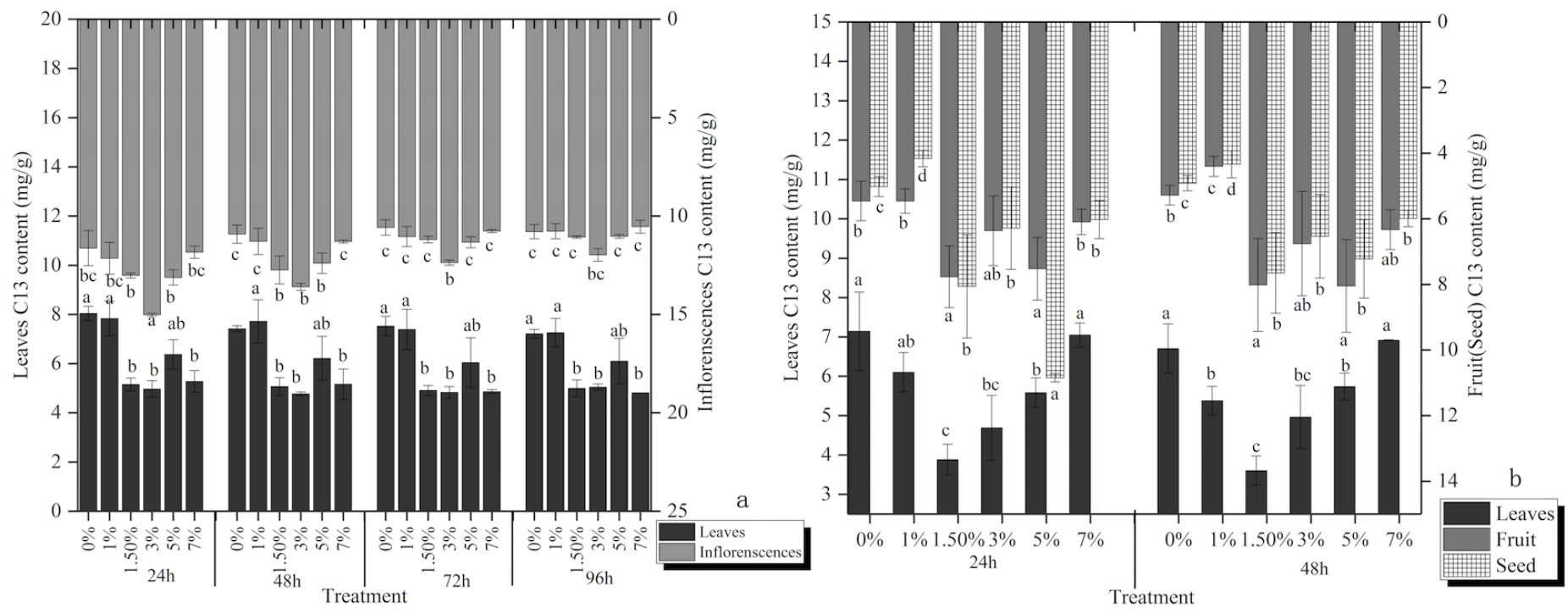

Figure 5

Comparison of $13 \mathrm{C}$ amounts in different organs after labelling for $24 \mathrm{~h}$ to $96 \mathrm{~h}$. (a) The black column indicates the leaf $13 \mathrm{C}$ value from $24 \mathrm{~h}$ to $96 \mathrm{~h}$ in DBB5. The grey column indicates the inflorescence $13 \mathrm{C}$ value from $24 \mathrm{~h}$ to $96 \mathrm{~h}$ in DBB5. (b) The black column indicates the leaf $13 \mathrm{C}$ value from $24 \mathrm{~h}$ to $48 \mathrm{~h}$ in DBFA5. The black column at the top indicates the fruit $13 \mathrm{C}$ value, and grey represents the seed $13 \mathrm{C}$ content. Vertical bars indicate standard errors. Different letters above the bars indicate significant differences between treatments based on Duncan's multiple range test at a $p$-value $<0.05$.
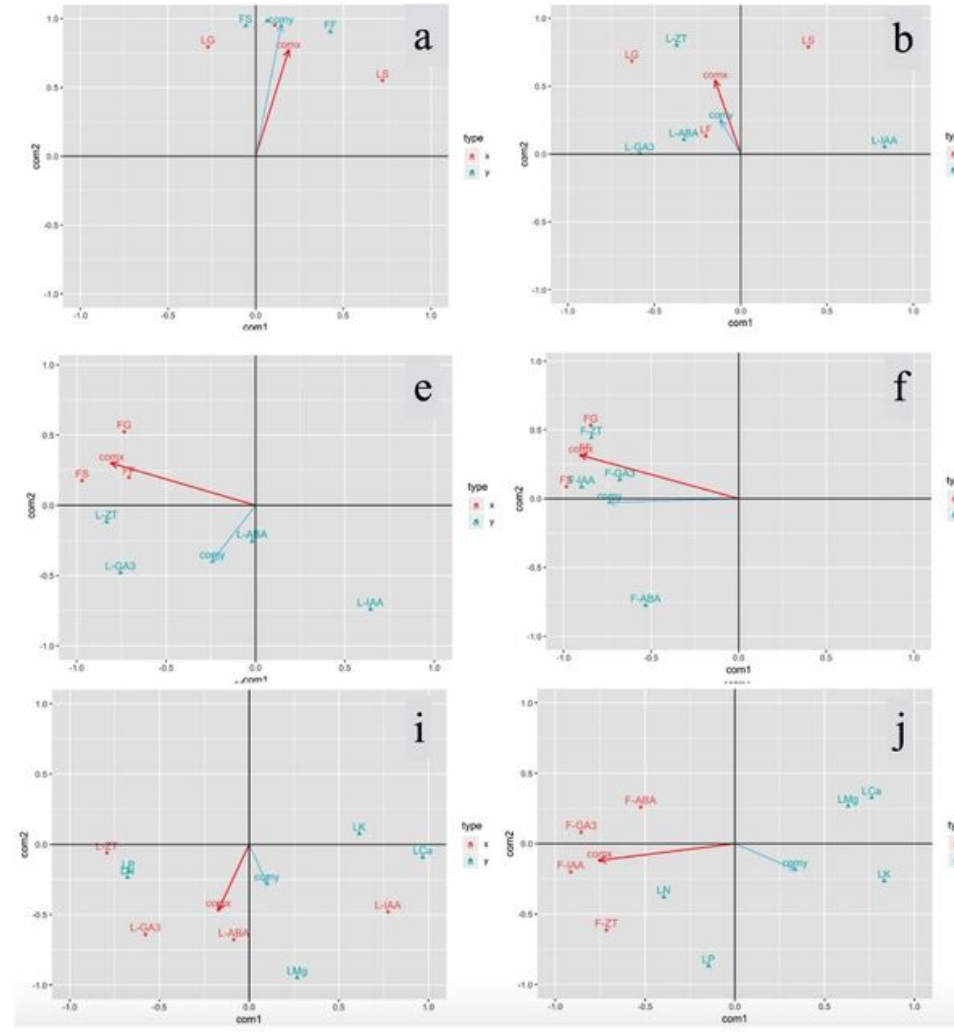
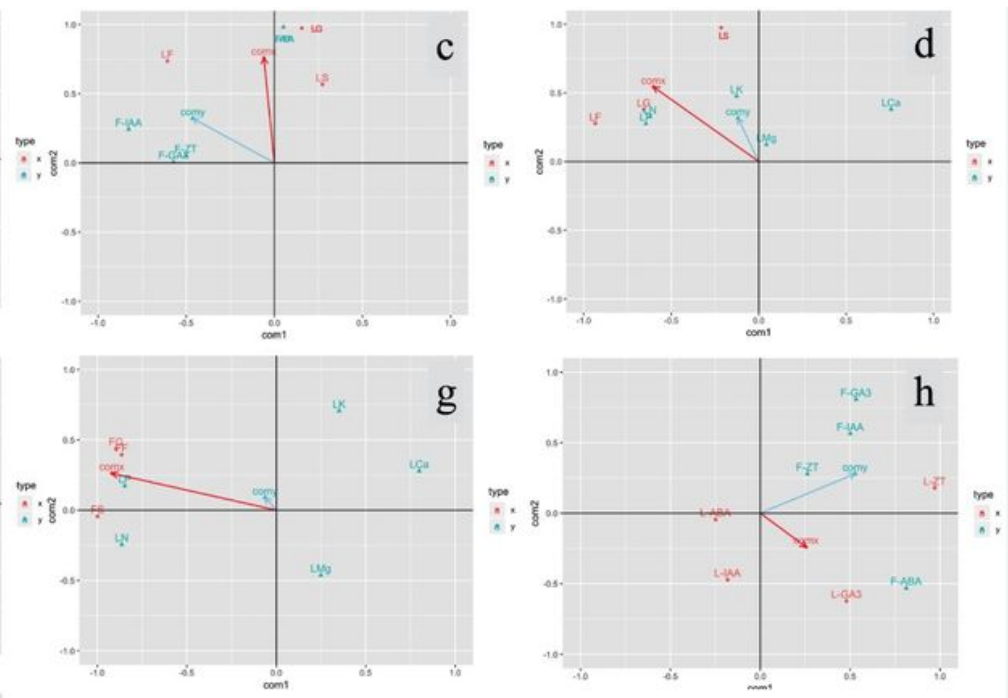

Figure 6 
Canonical correlation analysis (CCA) of leaf sugar, fruit sugar, leaf hormones, fruit hormones and leaf mineral elements. (a) CCA of leaf sugar and fruit sugar; comx indicates total leaf sugar, and comy indicates total fruit sugar. (b) CCA of leaf sugar and leaf hormones; comx indicates total leaf sugar, and comy indicates all leaf hormones. (c) CCA of leaf sugar and fruit hormones; comx indicates total leaf sugar, and comy indicates all the fruit hormones. (d) CCA of leaf sugar and leaf mineral elements; comx indicates total leaf sugar, and comy indicates all leaf mineral elements. (e) CCA of fruit sugar and leaf hormones; comx indicates total fruit sugar, and comy indicates all leaf hormones. (f) CCA of fruit sugar and fruit hormones; comx indicates total fruit sugar, and comy indicates all fruit hormones. (g) CCA of fruit sugar and leaf mineral elements; comx indicates total fruit sugar, and comy indicates all leaf mineral elements. (h) CCA of fruit hormones and leaf hormones; comx indicates total fruit hormones, and comy indicates all leaf hormones. (i) CCA of leaf hormones and leaf mineral elements; comx indicates total leaf hormones, and comy indicates total leaf mineral elements. (j) CCA of fruit hormones and leaf mineral elements; comx indicates total fruit hormones, and comy indicates total leaf mineral elements.

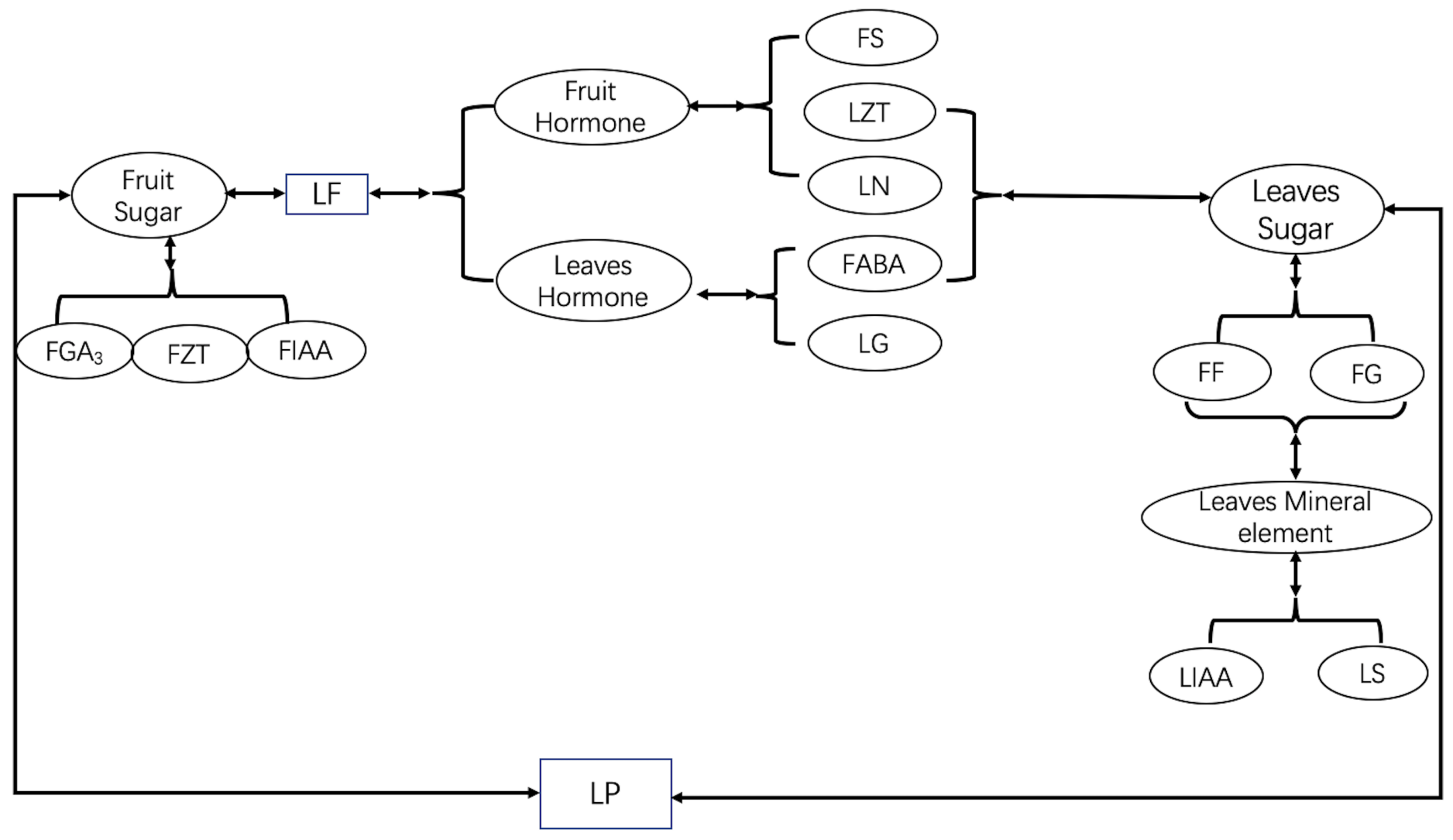

\section{Figure 7}

The pathways of main nutrition influences in leaves and fruits. Brackets indicate combined functions. Lines with arrows indicate the correlations between two factors. 


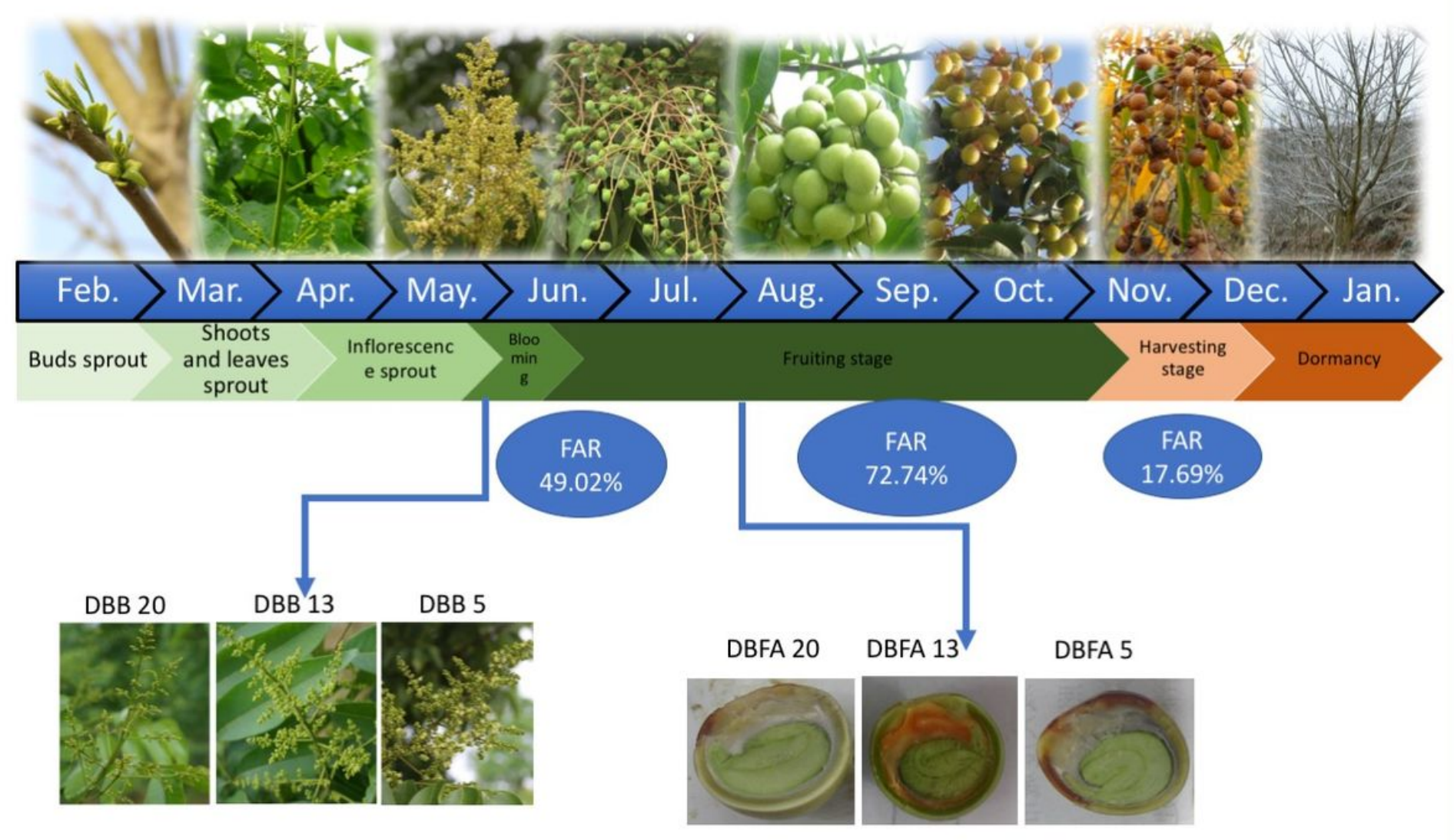

\section{Figure 8}

Major phenological stages of Sapindus mukorossi. The top three lines depict the important phenological stages throughout an entire year. FAR indicates the three fruit abscission rates stages measured from 2013-2015. The bottom six pictures show the 6 different times of sprayings sucrose. DBB refers to 20,13 and 5 days before the blooming stage; DBFA refers to 20,13 and 5 days before the fruit abscission stage. 